\title{
Changes in Inflammatory Response and Performance to Field Tests Induced by a Concomitant Training Block in Elite Handball Players in Benin
}

\author{
Linta Léonce Sèjro Odjouola ${ }^{1}$, Tonon Brigitte Affidéhomé ${ }^{*}{ }^{*}$, Hountohotegbé Tatiana ${ }^{2}$, \\ Gouthon Polycarpe1, Bigot Koffi Andrée, Nouatin Basile Kocou ${ }^{1}$, Bio Nigan Issiako' \\ ${ }^{1}$ Sport, Health and Evaluation Research Unit, (UR/SSE), National Institute of Youth, Physical Education and Sport, \\ University of Abomey-Calavi, Porto-Novo, Republic of Benin \\ ${ }^{2}$ Immunogenetics and Inflammation Laboratory, Faculty of Health Sciences, University of Abomey-Calavi, Cotonou, \\ Republic of Benin \\ Email: *affidehome@yahoo.fr
}

How to cite this paper: Odjouola, L. L. S., Affidéhomé, T. B., Tatiana, H., Polycarpe, G., André, B. K., Kocou, N. B., \& Issiako, B. N. (2021). Changes in Inflammatory Response and Performance to Field Tests Induced by a Concomitant Training Block in Elite Handball Players in Benin. Advances in Physical Education, 11, 489-502.

https://doi.org/10.4236/ape.2021.114040

Received: October 31, 2021

Accepted: November 27, 2021

Published: November 30, 2021

Copyright $\odot 2021$ by author(s) and Scientific Research Publishing Inc. This work is licensed under the Creative Commons Attribution International License (CC BY 4.0).

http://creativecommons.org/licenses/by/4.0/

\section{(c) (i) Open Access}

\begin{abstract}
The effects of different training methods on immune function in African elite handball players have been little evaluated. The aim of this study was to determine the effects of a six-week concomitant training (CT) block on parameters associated with the inflammatory response and performance on field tests in elite handball players in Benin. This was a controlled interventional study, undertaken with 18 international handball players (21.4 \pm 3.0 years), randomized into two groups: interventional (IG) and control (CG). Players of the intervention group (IG) participated in a concomitant training block (CT) and those who served as controls (CG), followed the usual content of their training sessions (UC). Interleukins Il-6 and Il-10, tumor necrosis factor (TNF- $\alpha$ ), as well as performance in five field tests, were determined at the beginning and end of the six-week of training. Changes in inflammatory response parameters recorded in IG were similar to those in CG (P > 0.05). Improvements recorded were greater in the IG group than in CG, for $\dot{\mathrm{V}} \mathrm{O}_{2}$ max $(+4.3 \%$ versus $+1.5 \% ; \mathrm{P}=0.01)$, medicine-ball throwing distance $(+15.9 \%$ versus $+4.3 \%$; $\mathrm{P}=0.004)$ and height in counter movement jump $(+7.0 \%$ versus $+0.5 \% ; \mathrm{P}=0.004)$. Handball coaches can therefore use concomitant training as an effective method of developing $\dot{\mathrm{VO}}_{2}$ max and explosive strength capacity without fearing an impairment of immune function in the handball players studied.
\end{abstract}




\section{Keywords}

Inflammatory Response, Fitness Capacity, Training Method, Handball, Sub-Saharan Africa

\section{Introduction}

In team sports, training aims to improve the performance capacity of athletes in competition. The achievement of performance requires a good interaction between training loads and recovery times, which induces the establishment of overcompensation favorable to progress (Mujika, Halson, Burke, Balagué, \& Farrow, 2018). On the other hand, failure to allow adequate recovery time can lead to undesirable situations such as overtraining. Overtraining is associated with adverse effects on immunological and biochemical parameters, leading to a decrease in performance capacity and an increased risk of physical damage, including damage to muscle function (Cadegiani, da Silva, Abrao, \& Kater, 2020). Elite players often use means such as balneotherapy, physiotherapy, massage and dietary techniques to speed up recovery (Walsh, 2019; Reilly, Drust, \& Clarke, 2008). Although it is often possible for them to use these techniques, training for elite handball players also includes sessions in which physical preparation sequences are integrated and especially those aimed at developing the capacity for quick recovery (Jidovtseff, 2013).

In Benin, the conditions under which handball players practice are not very favorable to the achievement of high-level performances (Nouatin, Gouthon, Amoussou-guenou, Dansou, Messan, Falola, Tonon, Nigan, \& Aremou, 2015). Indeed, the training time and number of sessions generally do not exceed respectively 8 hours and four per week. Strategies to accelerate recovery between training sessions, during a training camp for example, such as massages, cold baths and physiotherapy, are little accessible. It is therefore necessary to consider the use of training methods, which, while inducing the development of physical abilities, promote that of the rapid recovery capacity, because the work intensities are often close to those recorded during the matches.

These training methods promote a good stimulation of the physiological adaptation mechanisms of the players, allowing the rapid recovery of the body and more particularly that of muscle function, as well as the parameters associated with the inflammatory response (Khan, Moiz, Raza, Verma, Shareef, Anwer, \& Alghadir, 2016). Indeed, when the muscles are accustomed to a high level of effort during training sessions, the risk of injury to the muscle fibers during matches and the installation of the inflammatory process during recovery is reduced (Khan et al., 2016). One training method that, has emerged as suitable for the simultaneous development of rapid recovery of immune function, muscular capacities such as explosive strength of the pelvic and thoracic limbs, repeated sprints, running speed and maximum aerobic speed, is concomitant training 
(Methenitis, 2018; Sellami, Gasmi, Denham, Hayes, Stratton, Padulo, \& Bragazzi, 2018; Salamat, Azarbayjani, Yusof, \& Dehghan, 2016; Marin, Bolin, Campoio, Guerra, \& Otton, 2013; Buchheit, 2008). This method is generally, based on high intensity exercises, aiming consecutively at the development of maximal aerobic speed (MAS) and muscular strength in the same session (Methenitis, 2018). It also favors the development of the capacity for repeated sprints (Methenitis, 2018; Buchheit, 2008), physical fitness and athletic performance in children and particularly adolescents (Hebisz, Hebisz, Borkowski, \& Zatoń, 2019; Gäbler, Prieske, Hortobágyi, \& Granacher, 2018) and the improvement of the fatigue index, which is fundamental for the quick recovery of the body (Buchheit, 2008). Concomitant training resulted in reduced muscle damage in cyclists (Hebisz et al., 2019) and LDL with multiple cardiometabolic benefits in adults (Da Silva, Baptista, Neves, De França, Loureiro, Lira, Caperuto, Veríssimo, \& Martins, 2020).

Data on the effect of a concomitant training (CT) program on field-test performance and parameters associated with the inflammatory response of handball players in sub-Saharan Africa are rather scarce. Even in Europe, the few studies that have been conducted, using methods other than the one in this research, have explored only immune function (Sellami et al., 2018; Marin et al., 2013). However, research on the effect of concomitant training in healthy Iranian students reported a decrease in pro-inflammatory cytokines, including IL- 6 and TNF- $\alpha$ after 8 weeks (Salamat et al., 2016). Determining the effects of a concomitant training program on inflammatory responses and performance in field tests is also important if, maintaining good player health is a priority. This, in turn, will promote optimal performance. The aim of this study is therefore to determine the effects of a six-week concomitant training block on both parameters associated with the inflammatory response and performance in field tests in elite handball players in Benin.

\section{Materials et Methods}

\section{Protocol}

This is a controlled interventional study, conducted in Porto-Novo with junior and senior handball players, all belonging to the National elite of Republic of Benin. These players completed six weeks of training (concomitant training and/or usual content of training sessions). Before the intervention and 72 hours after the end of the last training session, five field tests and blood samples were taken from each player.

Body mass (BM) and rectal temperature (Trec) were measured before and just at the end of the training sessions. Resting $(\mathrm{HRr})$, maximum $\left(\mathrm{HR}_{\max }\right)$ and mean $(\mathrm{HRm})$ heart rates were recorded during the workout sequences and, drinking water was assessed at the end of each session. The study was conducted according to the recommendations of the Declaration of Helsinki (World Medical Association, 2013) as amended in 2013. The prior approval of the Sectorial Scientific Committee of Science and Techniques of Physical and Sports Activities of 
the University of Abomey-Calavi was required: $\mathrm{N}^{\circ} 043-2015 / \mathrm{UAC} / \mathrm{INJEPS/ED-}$ EPS-DH/D/SA.

\section{Participants}

The study was undertaken with 18 international handball players, 9 juniors and 9 seniors. To be included in the study sample, the following inclusion criteria had to be met: playing in the Republic of Benin Division 1 Championship and be a member of this nation under-21 (U21) or senior team of the current year and having played in international competition during the past season; giving their informed free consent form to participate in the study. The 18 players were randomly divided into two equal groups, i.e. an interventional group (IG) and a control group (CG). The IG group participated in some concomitant training (CT) sessions and the CG followed the usual content of their training sessions (UC). Players who were injured and/or ill were not included in the sample. Participants who were retained but subsequently missed more than 3 training sessions should be excluded.

\section{Blood Tests}

Each player had their last meal more than 3 hours before the start of their blood samples and each time five milliliters $(5 \mathrm{~mL})$ of blood was taken from each player by venipuncture from the left elbow into dry tubes. Blood in the dry tubes was centrifuged in the laboratory at $3000 \mathrm{tr} / \mathrm{min}$ for $10 \mathrm{~min}$ within one hour of collection to recover the serums, which were stored at $-80^{\circ} \mathrm{C}$ and then used for the determination of IL-6, IL-10 and TNF- $\alpha$ cytokines. Ready-Set-to-Go ELISA kits (Invitrogen ${ }^{\circledR}$ ) with microplates were used, to determine the serum concentrations of each cytokine according to the protocol proposed by the fabricant. The "Sandwich" ELISA technique has been used, for the more sensitive cytokines assay. The detection limits of the cytokines were $2 \mathrm{pg} / \mathrm{mL}$ for IL- 6 and IL-10 and $4 \mathrm{pg} / \mathrm{mL}$ for TNF- $\alpha$.

A Thermo Scientific TM WellwashTM versa microplate washer was used for plates washing after each step. At the end of the reaction, the optical densities of the product obtained for each cytokine were measured at $450 \mathrm{~nm}$ according to the supplier's recommendations, using a Tecan plate reader Infinite $\left(200 \mathrm{Pro}^{\circledR}\right)$ photometer and Tecan ${ }^{\circledR} \mathrm{i}$-control software version 1.12.4.0. Concentration curves obtained from the standards provided by the manufacturer (IL-6 from 2 to 200 $\mathrm{pg} / \mathrm{mL}$, IL-10 from 2 to $300 \mathrm{pg} / \mathrm{mL}$ and TNF- $\alpha$ from 4 to $500 \mathrm{pg} / \mathrm{mL}$ ) were used to determine the concentration of each cytokine using Excel ${ }^{\circledR}$ software (Excel, 2010 version).

\section{Field Tests}

Running times in the $30 \mathrm{~m}$ isolated and repeated sprints tests were measured with photoelectric cells (Brower Timing System, USA). The $30 \mathrm{~m}$ sprint test was performed in 3 separate $30 \mathrm{~s}$ trials and the best time, in seconds $\left(\mathrm{TSS}_{30}\right)$ was chosen. The repeated sprint capability test (RSC) selected for this study, consisted of six full-speed shuttle sprints over a $15 \mathrm{~m} \times 2$ distance, with $14 \mathrm{~s}$ of active recovery between runs (Spencer, Fitzsimons, \& Dawson, 2006). The performance 
criterion was the average running time $\left(\mathrm{MT}_{\mathrm{CSR}}\right)$, i.e. the cumulative time of the six $15 \mathrm{~m} \times 2$ running sequences divided by six, expressed in seconds.

An OptoJump Next device (Microgate, Italy) was used to perform the counter-movement jump (CMJ) test. The height (in $\mathrm{cm}$ ) of the best trial out of the five performed was used. The strength of the thoracic limbs was assessed with 3 $\mathrm{kg}$ medicine balls, according to the protocol proposed in the literature (Palao \& Valdes, 2013). Of the three tests in this protocol, the eccentric-contraction throw (ECT) which appears, to be the closest to the specific actions of handball, was chosen. It consisted of performing the throw in three attempts, each time with both arms moving from the front to the back. During the throws, the players were not allowed to change their starting position. A DVD/CD tape player and a pre-recorded USB key of the 30 - 15 IFT test (Buchheit, 2005) were used to estimate the $\dot{\mathrm{VO}}_{2} \max _{30-15 \mathrm{IFT}}$ indirectly in the field.

\section{Data Collected during Training Sessions}

Height was measured to the nearest millimeter, before the first training session, using a $206 \mathrm{M}$ wall stadiometer (Seca-Bodymeter, France). Body mass was measured to the nearest $100 \mathrm{~g}$, using an automatic person scale (Terraillon, China) in players wearing only shorts and a t-shirt then the percentage of weight loss (\%WL) was calculated at the end of each session. FT4 heart rate monitors (Polar, Finland) were used to measure resting ( $\mathrm{HRr})$ as well as mean $(\mathrm{HRm})$ and maximum $\left(\mathrm{HR}_{\max }\right)$ hearts rates during exercise. $\mathrm{HRr}$ measurements were taken in a seated position after a $15 \mathrm{~min}$ rest in a quiet and well-ventilated room. Automatic MT 101R thermometers (Hangzou Sejoy, China) for personal and individual use, allowed to measure rectal temperature (Trec). Hygienic arrangements were made to clean each thermometer with bleach and then $90^{\circ}$ alcohol before and after each use.

The Physiological Stress Index (PSI) was calculated according to the formula: PSI $=5\left(\right.$ Trec $\left.-\operatorname{Trec}_{0}\right)\left(39.5-\text { Trec }_{0}\right)^{-1}+5\left(\mathrm{HR}_{\mathrm{t}}-\mathrm{HR}_{0}\right)(180-\mathrm{Fc} 0)^{-1}$ with $\mathrm{Trec}_{0}$ and Trec representing rectal temperature before and after the test respectively, $\mathrm{HR}_{0}$ and $\mathrm{HR}_{\mathrm{t}}$, heart rate before and at the end of the training session (Moran, Shitzer, \& Pandolf, 1998). The PSI rating scale proposed by the authors was used to determine the level of heat stress experienced by the athletes during the training sessions. At the end of each training session, the players individually expressed their perception of the effort made on the Borg scale (Borg, 1970). Ambient temperature and relative humidity were recorded during each session, using a TP50 digital thermometer-hygrometer (Thermo Pro, France). The quantity of water drunk per player, based on the contents of individual $1.5 \mathrm{~L}$ bottles, was calculated by deduction from the remaining one.

\section{Content of Training Sessions}

Training sessions of 120 minutes each took place outdoors for six weeks, three times a week. Ambient temperature varied from $29^{\circ} \mathrm{C}$ to $32^{\circ} \mathrm{C}$ and the relative humidity from $72 \%$ to $81 \%$. Sessions were held at the same time for IG and CG in the afternoon from 4 to $6 \mathrm{pm}$, under the supervision of two National Team 
Coaches. For all groups, the exercises were performed at maximum speed. For all types of training sessions, 3 min handling of group, 10 min warm-up and 2 min cool-down were performed. During the six weeks:

- the IG group participated in a training block, consisting partly of the usual exercises offered to the players and partly of physical preparation sequences in the form of concomitant training (CT);

- the CG group had a training content consisting only of the usual exercises (UC) offered to the players.

\section{Usual Training Content (UC)}

The training sessions focused on improving technical and tactical skills in attack and defense. The usual training session consisted of three parts.

a) The first $30 \mathrm{~min}$ session consisted of sprints sequences over $5 \mathrm{~m}, 10 \mathrm{~m}$ and $30 \mathrm{~m}$, to maintain the ability of reaction, start and race speeds. These sequences were performed in 3 series of 5 to 8 repetitions each. The passive recovery time between two repetitions of sprints was $30 \mathrm{~s}$ to $60 \mathrm{~s}$ and the rest between two series was 2 to $3 \mathrm{~min}$.

b) The second part, lasting 55 minutes and organized after 5 minutes of stretching, was reserved for the development of technical and tactical attacking skills over three weeks, and then defense over the following three weeks. In attack, the players first carried out sequences to improve the quality of mid-distance shots (suspension shot from $9 \mathrm{~m}$, change of direction with a series of 6 shots on each side, i.e. at the right and left fullback positions). Then they performed a series of 6 passes at the fullback position and give-and-go with shooting, in 2-on-0 and 2-on-1 situations. In defense, the players first executed 1-on-1 sequences at the back posts, carried out in a series of 6 series per back post and per defender. Then they played man-to-man defense over the whole field, half the field, and then a third of the field, in a 3-on-3, 4-on-4, 5-on-5 game situations respectively for the sessions:

- $\mathrm{N}^{\circ} 1$ to 3 (6 series of 1-minute, with 3 minutes of active rest between series);

- No. 4 to 6 (4 series of 1 minute $30 \mathrm{~s}$, with 4 minutes $30 \mathrm{~s}$ of active rest between series);

- $\mathrm{N}^{\circ} 7$ to 9 (3 series of 2-minute, with 5 minutes of active rest between series).

c) The third part, which lasted 15 minutes, was reserved the implementation of the day's learnings on full court.

\section{Concomitant Training Block (CT)}

The aim was to develop physical and technical skills in defense and then in attack. The sessions were composed of three parts:

a) The first 30 minutes, i.e. $25 \%$ of the total training time, was reserved for concomitant training sequences, with muscle strengthening sequences in 15 minutes and maximum aerobic speed (MAS) development in 15 minutes.

- The muscle strengthening sequences included explosive and plyometric force (strength) as well as sheathing (muscle cladding) exercises performed in 2 series of 7 - 8 repetitions each. Passive recovery time between repetitions was 
$30 \mathrm{~s}$ and rest between series was 2 minutes.

- The sequences reserved for the development of the MAS included interval-training sprints performed in $10 \mathrm{~s}$ for the first three weeks, then in $15 \mathrm{~s}$ for the last three weeks, performed at $100 \%$ (sessions 1 to 3 ), $110 \%$ (sessions 4 to 6 ) and $120 \%$ (sessions 7 to 9 ) of the estimated MAS $_{30-15 \text { IFT, }}$ with active recovery in slow running for $10 \mathrm{~s}$ or $15 \mathrm{~s}$ between two repetitions and active rest (stretching and hydration) for 5 min between series.

b) The second part had the same content as the regular training program. It lasted 55 minutes ( $45 \%$ of the total time) and included after 5 minutes of stretching, sequences to improve the technico-tactical abilities of attack, then defense.

c) The third part, which lasting 15 minutes (12.5\% of the total time), was reserved for the global implementation of the day's learnings in full court game.

\section{Statistical Analysis}

The data were processed with the Satistica software (Stat Soft Inc., version 12). Descriptive results are presented as mean $(\mathrm{m}) \pm$ standard deviation $(\mathrm{s})$ for the characteristics of the handball players studied and mean $(\mathrm{m}) \pm$ Standard Error of the Mean (SEM) for the variables studied. The normality of the distribution of variables was checked using the Kolmogorov-Smirnov test. As the distribution was non-normal, the Wilcoxon rank test was used to make the comparisons within the groups, and then the U of Mann-Whitney test was used to compare the IG and CG groups. The significance level of the statistical tests was set at $\mathrm{p}<$ 0.05 .

\section{Results}

Regardless of the characteristic considered (Table 1), the differences observed

Table 1. Anthropometric characteristics and sports history of the handball players studied $(\mathrm{n}=18)$.

\begin{tabular}{cccc}
\hline & $\begin{array}{c}\text { Intervention group } \\
(\mathbf{n}=\mathbf{9})\end{array}$ & $\begin{array}{c}\text { Control group } \\
(\mathbf{n}=\mathbf{9})\end{array}$ & $\mathbf{P}$ \\
\hline Age (ans) & $21.6 \pm 3.3$ & $21.2 \pm 2.8$ & 0.85 \\
Height $(\mathrm{cm})$ & $177.2 \pm 6.6$ & $177.8 \pm 5.2$ & 0.92 \\
BMI $\left(\mathrm{kg} / \mathrm{m}^{2}\right)$ & $22.6 \pm 1.4$ & $23.5 \pm 3.3$ & 0.65 \\
Seniority in practice (ans) & $10.6 \pm 2.2$ & $10.0 \pm 3.3$ & 0.42 \\
WTH (heures) & $7.3 \pm 1.4$ & $6.4 \pm 0.8$ & 0.21 \\
$\dot{\mathrm{VO}}{ }_{2}$ max (mL/min/kg) & $55.4 \pm 2.5$ & $53.2 \pm 3.7$ & 0.15 \\
HRr (bpm) & $58.0 \pm 3.0$ & $59,0 \pm 2,0$ & 0.99 \\
\hline
\end{tabular}

The values in boxes represent mean values $(\mathrm{m}) \pm$ standard deviations $(\mathrm{s})$. $\mathrm{n}$ : sample size. BMI: Body Mass Index. WTH: Weekly Training Hourly. RHR: Resting Heart Rate. $\dot{V}_{2}$ max : Maximum oxygen consumption estimated indirectly. Control group: control without concomitant training. P: p-value. 
between the two groups of handball players studied were non-significant $(\mathrm{P}>$ $0.05)$.

In the IG group, the IL- 6 and TNF- $\alpha$ means decreased by $65.3 \%(P=0.007)$ and $47.9 \%(\mathrm{P}=0.007)$ respectively at the end of the CT block (Table 2). The same was true for the CG group at the end of the UC program for IL-6 (44.9\%; $\mathrm{P}=0.007)$ and TNF- $\alpha(54.2 \% ; \mathrm{P}=0.007)$. In contrast, IL-10 increased by $190.4 \%$ $(\mathrm{P}=0.01)$ in IG and $162.9 \%(\mathrm{P}=0.01)$ in CG. Changes in IL-6, TNF- $\alpha$ and IL-10 recorded in GI did not show significant differences $(P>0.05)$ with those observed in CG.

At the end of the training period (Figure 1), performance of the proposed tests was improved in each of the IG and CG groups $(\mathrm{P}<0.05)$. However, improvements recorded for $\dot{\mathrm{VO}}_{2} \max (+4.3 \%$ versus $+1.5 \%$; $\mathrm{P}=0.019)$, MBT $(+15.9 \%$ versus $+4.3 \% ; \mathrm{P}=0.004)$ and $\mathrm{CMJ}(+7.0 \%$ versus $+0.5 \% ; \mathrm{P}=0.004)$ were great in the IG group than in CG. The differences (Table 2) between the time decreases recorded in the two groups were not significant for $\operatorname{TSS}_{30}(-2.3 \%$ versus $-2.3 \% ; \mathrm{P}=0.26)$ and $\mathrm{MT}_{\mathrm{CSR}}(-3.5 \%$ versus $-5.0 \% ; \mathrm{P}=0.72)$.

Table 3 shows that the $\% \mathrm{HR}_{\max }$ that the players practiced was higher $(75.7 \pm$ 0.6 versus $72.5 \pm 0.5 ; \mathrm{P}=0.004$ ) during $\mathrm{CT}$ training in the IG group. On the Borg scale, the IG training scores also appeared to be higher than those in CG (13.3 \pm 0.2 versus $12.4 \pm 0.0 ; \mathrm{P}<0.01)$. The differences observed between the two groups IG and CG, were non-significant $(\mathrm{P}>0.05)$ for the other parameters recorded during the training sessions.

\section{Discussion}

This study was undertaken on the basis of the hypothesis that concomitant training induces in Benin's elite handball players, over a six-week period, the

Table 2. Changes in parameters associated with inflammatory response and field test performance $(\mathrm{n}=$ 18).

\begin{tabular}{|c|c|c|c|c|c|c|}
\hline & \multicolumn{3}{|c|}{ Intervention group $(n=9)$} & \multicolumn{3}{|c|}{ Control group $(n=9)$} \\
\hline & M1 & M2 & $\Delta \mathrm{IG}(\%)$ & M1 & M2 & $\Delta \mathrm{CG}(\%)$ \\
\hline TNF- $\alpha(\mathrm{pg} / \mathrm{L})$ & $37.1 \pm 3.0$ & $19.3 \pm 2.3^{\star *}$ & -47.9 & $34.1 \pm 2.4$ & $15.6 \pm 1.9^{\star *}$ & -54.2 \\
\hline Interleukin-6 (pg/L) & $9.8 \pm 0.6$ & $3.4 \pm 0.2^{\star *}$ & -65.3 & $15.8 \pm 1.0$ & $8.7 \pm 0.8^{\star *}$ & -44.9 \\
\hline Interleukin-10 (pg/L) & $2.1 \pm 0.1$ & $6.1 \pm 0.8^{\star}$ & +190.4 & $2.7 \pm 0.4$ & $7.1 \pm 1.0^{*}$ & +162.9 \\
\hline $\mathrm{TSS}_{30}(\mathrm{~s})$ & $4.3 \pm 0.0$ & $4.2 \pm 0.0^{*}$ & -2.3 & $4.3 \pm 0.1$ & $4.2 \pm 0.0^{*}$ & -2.3 \\
\hline $\mathrm{MT}_{\mathrm{RSC}}(\mathrm{s})$ & $5.6 \pm 0.0$ & $5.4 \pm 0.1^{* *}$ & -3.5 & $6.0 \pm 0.1$ & $5.7 \pm 0.0^{\star *}$ & -5.0 \\
\hline
\end{tabular}

The values in boxes represent means $(\mathrm{m}) \pm$ standard errors of the mean (SEM). n: sample size. $\Delta(\%)$ : percentage of variation between before and after the training period in each group. IG: Intervention Group. CG: Control Group without concomitant training. M1: measures before six weeks of training. M2: measures after six weeks of training. TNF- $\alpha$ : Tumor Necrosis Factor. TSS 30 : Time of Single Sprint on 30 meters. $\mathrm{TM}_{\mathrm{RSC}}$ : Mean Time of Repeat Sprint Capacity. ${ }^{*}$ : difference between the measures taken before and at the end of the training period, significant at $\mathrm{P}<0.05$ in the same group. ${ }^{* *}$ : difference between the measures taken before and at the end of the training period, significant at $\mathrm{P}<0.01$ in the same group. 


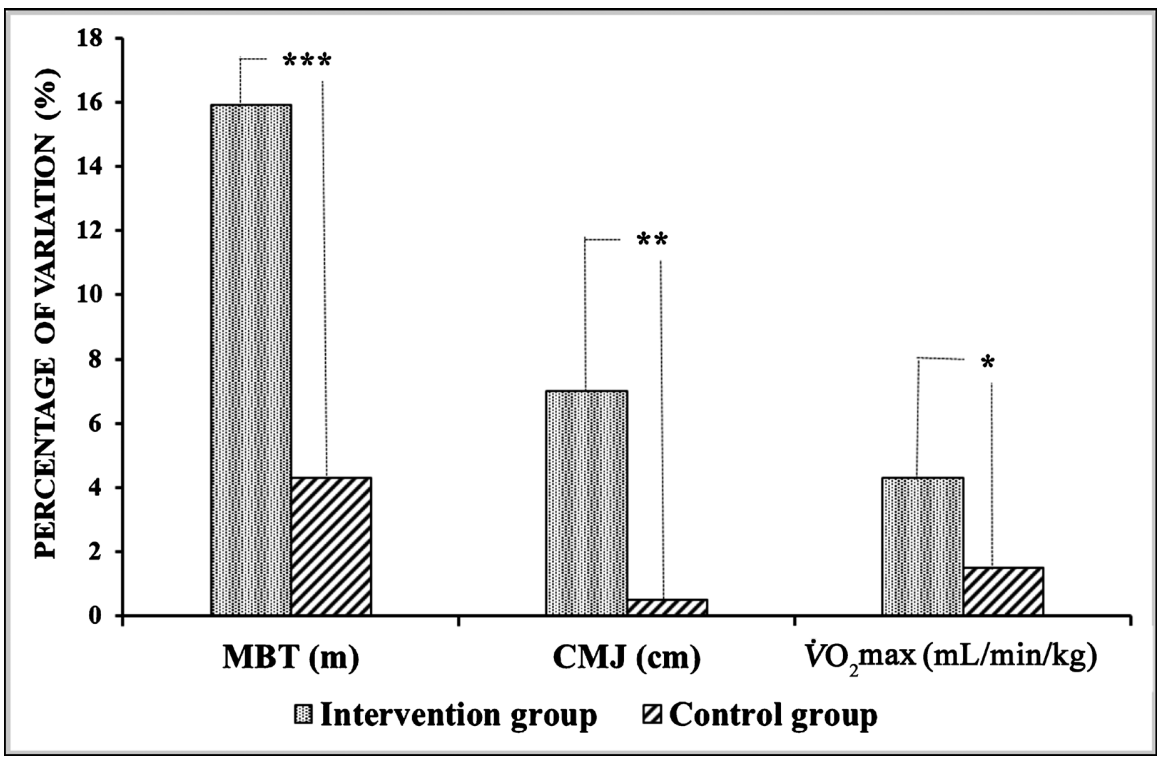

MBT: medicine ball throw by eccentric-concentric contraction; CMJ: counter movement jump; $\dot{\mathrm{V}} \mathrm{O}_{2} \max _{30-15 \mathrm{IFT}}$ : indirectly estimated of maximum oxygen consumption; *difference with Intervention group, significant at $\mathrm{P}<0.05$; ${ }^{* *}$ : difference with Intervention group, significant at $\mathrm{P}<0.01 ;{ }^{* *}$ : difference with Intervention group, significant at $\mathrm{P}<0.001$.

Figure 1. Changes in field-test performance: comparisons of percentage changes between IG and CG.

Table 3. Data means recorded in each group during the training sessions $(n=18)$.

\begin{tabular}{ccc}
\hline & $\begin{array}{c}\text { Intervention Group } \\
(\mathrm{n}=9)\end{array}$ & $\begin{array}{c}\text { Control group } \\
(\mathrm{n}=9)\end{array}$ \\
\hline Resting heart rate $(\mathrm{bpm})$ & $57.0 \pm 1.0$ & $57.0 \pm 1.0$ \\
Maximal heart rate $(\mathrm{bpm})$ & $195.0 \pm 0.0$ & $194.0 \pm 0.0$ \\
\% Maximal heart rate $(\mathrm{bpm})$ & $75.7 \pm 0.6$ & $72.5 \pm 0.5^{* *}$ \\
Rectal temperature $\left({ }^{\circ} \mathrm{C}\right)$ & $38.6 \pm 0.0$ & $38.4 \pm 0.0$ \\
$\operatorname{SPE}_{\text {BORG }}$ & $13.3 \pm 0.2$ & $12.4 \pm 0.0^{* * *}$ \\
Percentage of body mass losed $(\%)$ & $+0.1 \pm 0.2$ & $-0.1 \pm 0.1$ \\
Drunk Water $(\mathrm{L})$ & $2.5 \pm 0.1$ & $2.6 \pm 0.1$
\end{tabular}

The numbers in the boxes represent the mean values $(\mathrm{m}) \pm$ standard error of the mean (SEM). n: sample size. SPE $_{\mathrm{BORG}}$ : Subjective perception of the effort exerted during training sessions, according to the Borg scale [18]. Control group: Control without concomitant training. ${ }^{* *}$ : difference between control group and intervention group, significant at $\mathrm{P}<$ $0.01{ }^{* * *}$ : control group and intervention group, significant at $\mathrm{P}<0.001$.

production of pro- and anti-inflammatory cytokines in a similar way to that induced by the usual content of their training sessions, but improves performance in physical field tests to a greater extent. Elite handball players were chosen because of the high physical and psychological loads of training and competitions suspected of affecting the immune system if fatigue and stress are persistent. In effect, psychological stress associated with training and competition at the elite 
level may be an additive factor to the effects of intensive exercise on immune function, as well as lake of rest and good food intake (Gleeson, 2006; Nieman, 1997). The results obtained are valid only for the handball players included in the study sample since the non-random sample does not allow the generalization of the conclusions to all handball players in Benin. Players selected to undertake this study have a good level of practice, since the resting heart rate values recorded, lower than $60 \mathrm{bpm}$ and those of $\mathrm{V}_{2}$ max, between 50 and $60 \mathrm{~mL} / \mathrm{min} / \mathrm{kg}$, correspond to the data reported in well-trained athletes (Kenney, Wilmore, \& Costill, 2017; Sporis, Vuleta, Vuleta Jr, \& Milanović, 2010).

At the end of the six weeks of training, the difference between the modifications recorded in the intervention group and those observed in the control group was not significant for any of the parameters associated with the inflammatory response. However, significant variations were recorded in each group considered separately. Thus, it appeared that both training contents had a positive (anti-inflammatory) effect on the organism of the handball players studied. In both groups, the means of IL-10, cytokine with the strongest anti-inflammatory effect of the selected ones, were increased, thus protecting the players against inflammation (Sellami et al., 2018). This positive effect of both training contents is reinforced by the decrease in IL-6. This cytokine is pro-inflammatory (Cantagrel, Degboé, Constantin, \& Davignon, 2017) but also has anti-inflammatory effects, because it activates the production of classical anti-inflammatory cytokines such as the interleukin-1 antagonist (IL-1ra) and IL-10 (Pedersen \& Febbraio, 2008). The protective effect of these two contents was also enhanced by reducing the concentration of TNF- $\alpha$, an exclusively pro-inflammatory cytokine (Cantagrel et al., 2017).

IL-6 therefore probably contributed to the elevation of IL-10 in both groups at the end of the six weeks of training. IL-10 in turn would have inhibited the production of IL- 6 and TNF- $\alpha$ (Cantagrel et al., 2017). Thus, it is possible to deduce that the increase in IL-10 and subsequent decreases in IL- 6 and TNF- $\alpha$ are related to the fact that the anti-inflammatory effects induced by the two training contents are higher than those associated with the pro-inflammatory process, over the six-week period. This anti-inflammatory mechanism is probably related to the adaptation of skeletal muscles to training, which is responsible for the increase in levels of expression of the sensitivity of the receptors of the skeletal muscles to pro-inflammatory cytokines (Pedersen \& Febbraio, 2008). Training has therefore most likely made the muscles more resistant to the inflammatory process, as evidenced by the decrease in these two cytokines IL- 6 and TNF- $\alpha$. In a study that investigated the effect of concomitant training on pro-inflammatory cytokines, a decrease in IL- 6 and TNF- $\alpha$ was also reported after eight weeks (Salamat et al., 2016). The increase in IL-10, as well as the decreases in IL-6 and TNF- $\alpha$ levels in both groups in the present study can therefore be considered positive for the immune system. It was also found that in the handball players studied, the concomitant training did not stress the body more than the usual 
content of their training sessions over a period of six weeks. If the two contents had similar effects with regard to the induced inflammatory response, it is reasonable to investigate which aspects the concomitant training block had an additional or specific positive effect on.

At the end of the six weeks of training, improvements in $\dot{\mathrm{VO}}_{2}$ max, medicine ball throwing and counter-movement jump were greater in the concomitant training group than in the control group. These differences certainly account for the effectiveness of concomitant training on maximal aerobic power and explosive strength test performance in Benin's elite, but intermediate level, players who used this method for 30 minutes per session. The greatest improvements observed in the intervention group are probably associated with the content of the concomitant training block. The sequences aimed at developing maximum aerobic speed, i.e. maximum speed race in the short-course modality of intermittent training, performed in $10 \mathrm{~s}$ or $15 \mathrm{~s}$, during the six-week block may account for much of the greater improvement in $\dot{\mathrm{V}}_{2}$ max recorded. Intermittent training is indeed very effective in ensuring the selective development of $\dot{\mathrm{VO}}_{2}$ max (Methenitis, 2018).

The plyometric exercises practiced by the players in the intervention group certainly caused the improvements in performance recorded in counter-movement jump and then in eccentric-contraction throwing. These are indeed flexion-extension exercises, commonly called push-ups, for the thoracic limbs, and bench and multi-jump exercises for the pelvic limbs. All of these exercises involve contractions that place significant demands on the elastic elements of the muscles (Castagna \& Castellini, 2013). The increase in performance in eccentric-contraction throwing and counter-movement jump in the intervention group may also be partly associated with the effects of the joint work sequences, devoted to learning the techniques of shooting, counter-shooting and one-on-one attack.

In each group, similar improvements in the $30 \mathrm{~m}$ sprint time and in the mean time of the six sprints in the repeated sprint capacity test were recorded. These improvements in each group can be attributed to the combined effects of sprints aimed at developing $\dot{\mathrm{VO}}_{2} \max$ in players assigned to the concomitant training and the sprints at maintaining running speed in the control group. It has been reported that, sprint repetition training improves the best single sprint time (Mohr, Krustrup, Nielsen, Nybo, Rasmussen, Juel, \& Bangsbo, 2007), as well as the mean time over several consecutive sprints more than interval training (Buchheit, Mendez-Villanueva, Quod, Quesnel, \& Ahmaidi, 2010). Other authors, however, believe that intermittent training is better than the sprint repetition method because it improves not only running speed but also the fatigue index (Buchheit, 2008).

In this study, concomitant training showed its potential to improve maximal aerobic speed in the short term, followed by explosive strength of the thoracic and pelvic limbs. It didn't, therefore, further improve the starting and running 
speed capabilities of the handball players studied. Under this study conditions, in relation to immune function, the handball players studied can use both training contents since they did not negatively affect the parameters associated with the inflammatory response. However, if they wish to improve physical capabilities, concomitant training is preferable to develop $\dot{\mathrm{VO}}_{2}$ max and explosive strength capabilities. Therefore, they will need to use other methods such as combined training to develop the starting and running speed abilities, which are considered to be, determinants of handball performance (Dawson, 2012).

\section{Conclusion}

The objective of this study was to determine the effects of a six-week block of concomitant training on parameters associated with the inflammatory response and performance in field tests in elite handball players in Benin. The results confirm the research hypothesis that concomitant training induces pro- and antiinflammatory cytokine production in Beninese elite handball players over six weeks in a similar way to that induced by the usual content of their training sessions, but further improves performance in physical field tests. However, this improvement in performance was limited to tests of explosive strength capacity and maximal aerobic power. These results suggest that coaches can use this method to develop these physical abilities in their players without affecting their immune function. However, a more effective method of improving sprinting and repeated sprinting skills in this category of handball players will need to be sought.

\section{Acknowlegments}

The authors would like to thank all the players, coaches and managers of the handball clubs who agreed to participate in this study, giving up their time and energy.

\section{Conflicts of Interest}

The authors declare no conflicts of interest regarding the publication of this paper.

\section{References}

Borg, G. (1970). Perceived Exertion as an Indicator of Somatic Stress. Scandinavian Journal of Rehabilitation Medicine, 2, 92-98. https://doi.org/10.1037/t58166-000

Buchheit, M. (2005). Le 30-15 Intermittent Fitness Test. Approches du Handball, 89, 42-47.

Buchheit, M. (2008). 30-15 Intermittent Fitness Test and Repeated Sprint Ability. Science \& Sports, 23, 26-28. https://doi.org/10.1016/j.scispo.2007.12.002

Buchheit, M., Mendez-Villaneuva, A., Quod, M., Quesnel, T., \& Ahmaidi, S. (2010). Improving Acceleration and Repeated Sprint Ability in Well-Trained Adolescent Handball Players: Speed vs. Sprint Interval Training. International Journal of Sports Physiology and Performance, 5, 152-164. https://doi.org/10.1123/ijspp.5.2.152

Cadegiani, F. A., da Silva, P. H. L., Abrao, T. C. P., Camargo, T., Abrao, P., \& Kater, C. E. 
(2020). Diagnosis of Overtraining Syndrome: Results of the Endocrine and Metabolic Responses on Overtraining Syndrome Study: Eros-Diagnosis. Journal of Sports Medicine, 2020, Article ID: 3937819. https://doi.org/10.1155/2020/3937819

Cantagrel, A., Degboé, A., Constantin. A., \& Davignon, J. L. (2017). Le TNF- $\alpha$, L'Interleukine-6 et L'Interleukine-1: Trois Cytokines Centrales de la Polyarthrite Rhumatoïde. Revue du Rhumatisme Monographies, 84, 325-330.

https://doi.org/10.1016/j.monrhu.2017.08.005

Castagna, C., \& Castellini, E. (2013). Vertical Jump Performance in Italian Male and Female National Team Soccer Player. Journal of Strength and Conditioning Research, 27, 1156-1161. https://doi.org/10.1519/JSC.0b013e3182610999

Da Silva, M. A. R., Baptista, L. C., Neves, R. S., De França, E., Loureiro, H., Lira, F. S., Caperuto, E. C., Veríssimo, M. T., \& Martins, R. A. (2020). The Effects of Concurrent Training Combining Both Resistance Exercise and High-Intensity Interval Training or Moderate-Intensity Continuous Training on Metabolic Syndrome. Frontiers in Physiology, 11, Article No.572. https://doi.org/10.3389/fphys.2020.00572

Dawson, B. (2012). Repeated-Sprint Ability: Where Are We? International Journal of Sports Physiology and Performance, 7, 285-289. https://doi.org/10.1123/ijspp.7.3.285

Gäbler, M., Prieske, O., Hortobágyi, T., \& Granacher, U. (2018). The Effects of Concurrent Strength and Endurance Training on Physical Fitness and Athletic Performance in Youth: A Systematic Review and Meta-Analysis. Frontiers in Physiology, 9, Article No. 1057. https://doi.org/10.3389/fphys.2018.01057

Gleeson, M. (2006). Immune System Adaptation in Elite Athletes. Current Opinion in Clinical Nutrition and Metabolic Care, 9, 659-665. https://doi.org/10.1097/01.mco.0000247476.02650.18

Hebisz, R., Hebisz, P., Borkowski, J., \& Zatoń, M. (2019). Effects of Concomitant HighIntensity Interval Training and Sprint Interval Training on Exercise Capacity and Response to Exercise-Induced Muscle Damage in Mountain Bike Cyclists with Different Training Backgrounds. Isokinetics and Exercise Science, 27, 21-29. https://doi.org/10.3233/IES-183170

Jidovtseff, B., Frère, P., \& Theunissen, C. (2013). The Use of Resistance Training in Amateur Level Team Sports: The Example of Female Handball. Science \& Sports, 28, 281-290. https://doi.org/10.1016/j.scispo.2013.06.003

Kenney, L., Wilmore, J., \& Costill, D. (2017). Physiology of the Sport and the Exercise (6th ed., pp. 149-261). De Boeck University.

Khan, M. A., Moiz, J. A., Raza, S., Verma, S., Shareef, M. Y., Anwer, S., \& Alghadir, A. (2016). Physical and Balance Performance Following Exercise Induced Muscle Damage in Male Soccer Players. Journal of Physical Therapy Science, 28, 2942-2949.

https://doi.org/10.1589/jpts.28.2942

Marin, D. P., Bolin, A. P., Campoio, T. R., Guerra, B. A., \& Otton, R. (2013) Oxidative Stress and Antioxidant Status Response of Handball Athletes: Implications for Sport Training Monitoring. International Immunopharmacology, 17, 462-470. https://doi.org/10.1016/j.intimp.2013.07.009

Methenitis, S. (2018). A Brief Review on Concurrent Training: From Laboratory to the Field. Sports, 6, Article No. 127. https://doi.org/10.3390/sports6040127

Mohr, M., Krustrup, P., Nielsen, J. J., Nylo, L., Rasmussen, M. K., Juel, C., \& Bangsbo, J. (2007). Effect of Two Different Intense Training Regimens on Skeletal Muscle Ion, Transport Proteins and Fatigue Development. American Journal of Physiology. Regulatory, Integrative and Comparative Physiology, 292, 1594-1602.

https://doi.org/10.1152/ajpregu.00251.2006 
Moran, D. S., Shitzer, A., \& Pandolf, K. B. (1998). A Physiological Strain Index to Evaluate Heat Stress. The American Journal of Physiology, 275, R129-R134. https://doi.org/10.1152/ajpregu.1998.275.1.R129

Mujika, I., Halson, S., Burke, L. M., Balagué, G., \& Farrow, D. (2018). An Integrated, Multifactorial Approach to Periodization for Optimal Performance in Individual and Team Sports. International Journal of Sports Physiology and Performance, 13, 538-561. https://doi.org/10.1123/ijspp.2018-0093

Nieman, D. C. (1997). Exercise Immunology: Practical Applications. International Journal of Sports Medicine, 18, S91-S100. https://doi.org/10.1055/s-2007-972705

Nouatin, B., Gouthon, P., Amoussou-Guénou, D., Dansou, P., Messan, F., Falola, J. M., Tonon, B. A., Nigan, B., \& Arèmou, M. (2015). Changes and Recovery in Fitness Capacities Following a Series of Handball Matches Played in the Sub-Tropical Climate by Division 1 Amateur Players. Journal Biology of Exercise, 11, 1-14.

Palao, J. M., \& Valdes, D. (2013). Testing Protocol for Monitoring Upper-Body Strength Using Medicine-Balls. Journal of Human Sport \& Exercise, 8, 335-341. https://doi.org/10.4100/jhse.2012.82.02

Pedersen, B. K., \& Febbraio, M. A. (2008). Muscle as an Endocrine Organ: Focus on Muscle-Derived Interleukin-6. Physiological Reviews, 88, 1379-1406.

https://doi.org/10.1152/physrev.90100.2007

Reilly, T., Drust, B., \& Clarke, N. (2008). Muscle Fatigue during Football Match-Play. Sports Medicine, 38, 357-367. https://doi.org/10.2165/00007256-200838050-00001

Salamat, K. M., Azarbayjani, M. A., Yusof, A., \& Dehghan, F. (2016). The Response of Pre-Inflammatory Cytokine Factors to Different Exercises (Endurance, Resistance, Concurrent) in Overweight Men. Alexandria Journal of Medicine, 52, 367-370. https://doi.org/10.1016/j.ajme.2015.12.007

Sellami, M., Gasmi, M., Denham, J., Hayes, L., D., Stratton, D., Padulo, J., \& Bragazzi, N. (2018). Effects of Acute and Chronic Exercise on Immunological Parameters in the Elderly Aged: Can Physical Activity Counteract the Effects of Aging? Frontiers in Immunology, 9, Article No. 2187. https://doi.org/10.3389/fimmu.2018.02187

Spencer, M., Fitzsimons, M., \& Dawson, B. (2006). Reliability of a Repeated-Sprint Test for Field Hockey. Journal of Science and Medicine in Sport, 9, 181-184. https://doi.org/10.1016/j.jsams.2005.05.001

Sporis, G., Vuleta, D., Vuleta, D., \& Milanović, D. (2010). Fitness Profiling in Handball: Physiological Characteristics of Elite Players. Collegium Antropologicum, 34, 1009-1014.

Walsh, N. P. (2019). Nutrition and Athlete Immune Health: New Perspectives on an Old Paradigm. Sports Medicine, 49, 153-168. https://doi.org/10.1007/s40279-019-01160-3

World Medical Association (2013). Declaration of Helsinki: Ethical Principles for Medical Research Involving Human Subjects.

https://www.wma.net/wp-content/uploads/2016/11/DoH-Oct2013-JAMA.pdf 